\title{
Body mass index and metabolic parameters in patients with schizophrenia during long-term treatment with paliperidone palmitate
}

\author{
Jennifer Kern Sliwa ${ }^{1 *}$, Dong-Jing Fu', Cynthia A Bossie ${ }^{1}$, Ibrahim Turkoz ${ }^{2}$ and Larry Alphs ${ }^{1}$
}

\begin{abstract}
Background: There is a strong association between weight gain and metabolic events in patients with schizophrenia receiving many of the second-generation antipsychotic agents. We explored the relationship between body mass index (BMI) and metabolic events in patients with schizophrenia receiving long-acting injectable paliperidone palmitate (PP) in a long-term trial.

Methods: We conducted a post hoc analysis of data from a PP study that included a 33-week open-label transition (TR) and maintenance phase; a variable duration, randomized, double-blind (DB), placebo-controlled phase and a 52-week open-label extension (OLE) phase. Overall, 644 patients received PP continuously from study entry through discontinuation or study completion and were grouped by baseline $\mathrm{BMI}\left(\mathrm{kg} / \mathrm{m}^{2}\right)$ : underweight $(\mathrm{BMI}<19 ; \mathrm{n}=29$, 4.5\%), normal-weight (BMI 19- $<25 ; n=229,35.6 \%)$, overweight (BMI 25- $<30 ; n=232,36.0 \%$ ) and obese (BMI $\geq 30$; $\mathrm{n}=154,23.9 \%$ ). Metabolic treatment-emergent adverse events (TEAEs) and changes in related laboratory results from TR baseline were analyzed.
\end{abstract}

Results: PP exposure was similar across BMI groups; overall mean (SD) dose/month was 70.3 (17.17) mg eq. [109.6 (26.78) mg]; median duration of exposure was 204 days (6 to 1009 days). Occurrences of metabolic TEAEs overall by group were $0 \%$ (underweight), 14.9\% (normal-weight), 14.7\% (overweight), and 24.0\% (obese). The most common ( $\geq 2 \%$ ) metabolic TEAE were weight gain and elevated blood levels of glucose, lipids, and insulin. Mean BMl and weight increased in normal-weight and overweight groups at DB endpoint, and in underweight, normal-weight and overweight groups at OLE endpoint ( $p \leq 0.05$ ). No consistent trend for increased metabolic-related laboratory values by baseline BMl group was observed. Homeostatic model assessments for insulin resistance indicated preexisting insulin resistance at baseline, with minimal changes at OLE endpoint across baseline BMl groups.

Conclusion: Occurrences of metabolic-related TEAEs trended with greater BMI status in patients with schizophrenia treated with PP; consistent trends in metabolic-related laboratory values were not observed.

Trial registration: This study is registered at ClinicalTrials.gov (NCT 00518323).

Keywords: Body mass index, Metabolic, Paliperidone, Schizophrenia, Weight

\section{Background}

Schizophrenia is a chronic mental illness that requires long-term antipsychotic treatment to both manage disease symptoms and delay relapses [1]. Second generation antipsychotics (SGAs) are generally preferred over typical antipsychotics for schizophrenia treatment as they are associated with fewer extrapyramidal symptoms, lower

\footnotetext{
* Correspondence: jkernsli@its.jnj.com

'Janssen Scientific Affairs, LLC, NJ, USA

Full list of author information is available at the end of the article
}

risk of tardive dyskinesia, and possibly greater improvement in negative symptoms [2]. However, several SGAs are known to be associated with a high risk of metabolic adverse effects such as weight gain, hyperlipidemia and hyperglycemia [2,3]. Glucose dysregulation [4], glucose intolerance [5] and increased cholesterol levels [6] can occur in patients taking SGAs and there is a high prevalence of metabolic syndrome, especially in women (52\%) compared with men (36\%) with schizophrenia [7]. Additionally, obese and overweight

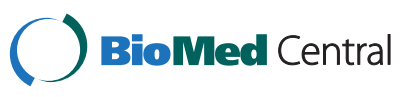


patients with schizophrenia are at a higher risk of metabolic adverse effects than those with normalweight [8]. These metabolic complications increase the risk for cardiovascular diseases, insulin resistance and diabetes mellitus, and can lead to increased morbidity and mortality, in addition to impairing patient adherence to medication [9]. Several consensus panels have recommended regular monitoring of metabolic biomarkers in patients with schizophrenia [10-12].

Paliperidone palmitate (PP), a long-acting injectable (LAI) administered once-monthly (after an initiation regimen of two injections: 150 milligram equivalents (mg eq.) [234 mg] on day 1, followed by $100 \mathrm{mg}$ eq. [156 mg] one week later), has been shown to be effective for the treatment of schizophrenia [13]. We conducted a post hoc analysis of data from a long-term (up to 3 years) multiphase, recurrence prevention study $[14,15]$ to examine the metabolic effects of extended PP treatment in patients with schizophrenia and the association of pre-treatment BMI status on metabolic events.

\section{Methods}

\section{Study population}

The inclusion and exclusion criteria for patients included in this study are reported in detail elsewhere $[14,15]$. In brief, men and women, aged 18 to 65 years (inclusive), having BMI $\geq 15.0 \mathrm{~kg} / \mathrm{m}^{2}$ with a diagnosis of schizophrenia (Diagnostic and Statistical Manual of Mental Disorders, 4th Edition [DSM-IV], criteria) for at least 1 year before screening, and a Positive and Negative Syndrome Scale (PANSS) total score below 120, at screening and baseline were included. Patients were excluded if they had an active DSM-IV diagnosis other than schizophrenia or significant risk of suicidal or aggressive behavior or a suspected history of substance dependence according to the DSM-IV criteria in the 3 months before screening.

For this post hoc analysis, patients who received PP continuously from study entry through discontinuation or study completion were included. Data were grouped according to patients' baseline BMI: underweight (BMI $<19 \mathrm{~kg}$ / $\mathrm{m}^{2}$ ), normal-weight (BMI $19-<25 \mathrm{~kg} / \mathrm{m}^{2}$ ), overweight (BMI $\left.25-<30 \mathrm{~kg} / \mathrm{m}^{2}\right)$ and obese $\left(\mathrm{BMI} \geq 30 \mathrm{~kg} / \mathrm{m}^{2}\right)$.

The study protocol was approved by an Independent Ethics Committee (Comité Ético Científico Universidad de Ciencias Médicas [UCIMED], Costa Rica; Comité de Ética del Centro de Investigación y Extensión de Ciencias de la Salud del Instituto Tecnológico de Estudios Superiores de Monterrey, Mexico; Comité de Enseñanza, Investigación, Capacitación y Ética, Comité de Ética e Investigación Clínica, Mexico; Clinical Trials Department- National Medicines Agency/The National Ethics Committee for the Clinical Trial Study of Medicines,
Romania; Independent Interdisciplinary Committee on Ethical Expertise of Clinical Studies, Russia; Pharma-Ethics, South Africa; Central Ethics Commission of the Ministry of Public Health of Ukraine Kornatskyy, Ukraine) or Institutional Review Board (Korea, Taiwan, Sterling Institutional Review Board, USA) at each study site; ethical standards were followed in accordance with the Declaration of Helsinki and consistent with ICH Good Clinical Practices, along with local regulatory requirements. All participants provided written informed consent.

\section{Study medication and design}

Doses of PP can be expressed both in terms of milligrams of PP and milligram equivalents of the pharmacologically active fraction, paliperidone; $39,78,117,156$, and $234 \mathrm{mg}$ doses of PP equate to $25,50,75,100$, and $150 \mathrm{mg}$ eq. of paliperidone, respectively.

The study consisted of a 9-week open-label transition (TR) phase, a 24-week open-label maintenance phase, a randomized double-blind (DB), placebo-controlled, relapse prevention phase of variable duration, and an optional 52-weeks open-label extension (OLE) phase. In the open-label TR phase, the eligible patients were switched from their previous antipsychotic to an initial regimen of $50 \mathrm{mg}$ eq. PP on days 1 and 8 in the gluteal muscle, followed by a flexibly-dosed PP $(25,50$, or $100 \mathrm{mg}$ eq.) once-monthly, in the gluteal muscle. Patients with stable PANSS score (defined as $\leq 75$ at week 9) entered the maintenance phase and received flexiblydosed PP for the first 12 weeks, with dose adjustments based on patient's clinical need, followed by 12 weeks of treatment at the established dose. Patients who were stable on fixed dose PP during the maintenance phase were randomized in a $1: 1$ ratio to continue to receive PP once-monthly or placebo. In the OLE phase, patients received initial dose of $50 \mathrm{mg}$ eq. followed by flexible-dose of 25, 50, 75, or $100 \mathrm{mg}$ eq. PP once-monthly. Doses were titrated up or down in increments of $25 \mathrm{mg}$ eq. at the investigator's discretion once-monthly for 12 dosing intervals.

\section{Data analysis}

Only patients who received PP continuously from study entry through discontinuation or study completion in the DB and OLE phases were included in data analyses using intent-to-treat (ITT) analysis set, which included patients who received at least 1 dose of PP during the study.

Metabolic treatment-emergent adverse events (TEAEs) were identified using Medical Dictionary for Regulatory Activities (MedRA) preferred terms. All adverse events that occured between the trial reference start and end date were included. Changes in weight, BMI, glucose, 
and lipid levels from TR baseline to DB endpoint and OLE endpoint were analyzed using a paired $t$-test; no multiplicity adjustment was incorporated. No betweengroup comparisons were conducted. The effect of PP on glucose homeostasis was assessed by homeostatic model assessments (HOMA), which measured insulin resistance (HOMA-IR) and $\beta$-cell function (HOMA- $\% \beta$ ) [16]. The HOMA-IR and HOMA- $\% \beta$ values were summarized descriptively. Unadjusted geometrics means and ranges were provided for HOMA-IR and HOMA- $\% \beta$. This method was applied across all ethnic groups.

\section{Results}

\section{Patient disposition, baseline characteristics and demographics}

A total of 644 patients met the criteria for inclusion in this analysis, of which 183 completed the study through OLE endpoint. Patient's choice was the most common (23\%) reason for discontinuation, followed by discontinuation due to adverse event (8\%) (Figure 1). Only one patient in the overweight group discontinued due to a metabolicrelated adverse event (weight gain) during the DB phase. Majority of patients were men (59\%) and white (60\%). The baseline demographic and clinical characteristics were similar across the groups, except race (Table 1). There was a higher proportion of blacks in the obese group compared with other races. The overall mean (SD) dose of PP during the study was 70.3 (17.17) $\mathrm{mg}$ eq. per month. The median duration of PP exposure during the study was 204 days (6 to 1009 days). The mean doses and median duration of PP exposure were similar among all the BMI-based groups.

\section{Treatment-emergent adverse events}

At least one TEAE from TR baseline to OLE endpoint was reported in more than $70 \%$ of patients in each of the BMI groups, except in the underweight group (55\%). The most frequently occurring TEAEs ( $\geq 5 \%$ overall) were insomnia (18\%), anxiety (13\%), worsening of schizophrenia (11\%) and psychotic disorders $(6 \%)$. Other TEAEs reported in $\geq 5 \%$ of patients in any of the BMI groups were agitation, hallucination, paranoia, headache, dizziness, akathisia, increased weight, nasopharyngitis and nausea (Figure 2, Additional file 1). Two patients in the normal-weight group and one patient in the obese group died during the open-label phase of the study (committed suicide $[\mathrm{n}=1]$, accident $[\mathrm{n}=1]$ and stroke $[n=1])$. No clear association of higher baseline BMI with increasing incidence of commonly occurring TEAEs was observed in the study.

However, the occurrence of metabolic-related TEAEs appeared to differ by BMI status. The obese group experienced the highest overall rate $(n=37 / 154,24 \%)$ of any metabolic TEAEs and highest rate of most of the specific metabolic-related TEAEs (Figure 3). The overall incidence of metabolic-related TEAEs for the normal-weight $(\mathrm{N}=34 / 229,14.9 \%)$ and the overweight group $(\mathrm{N}=34$ /

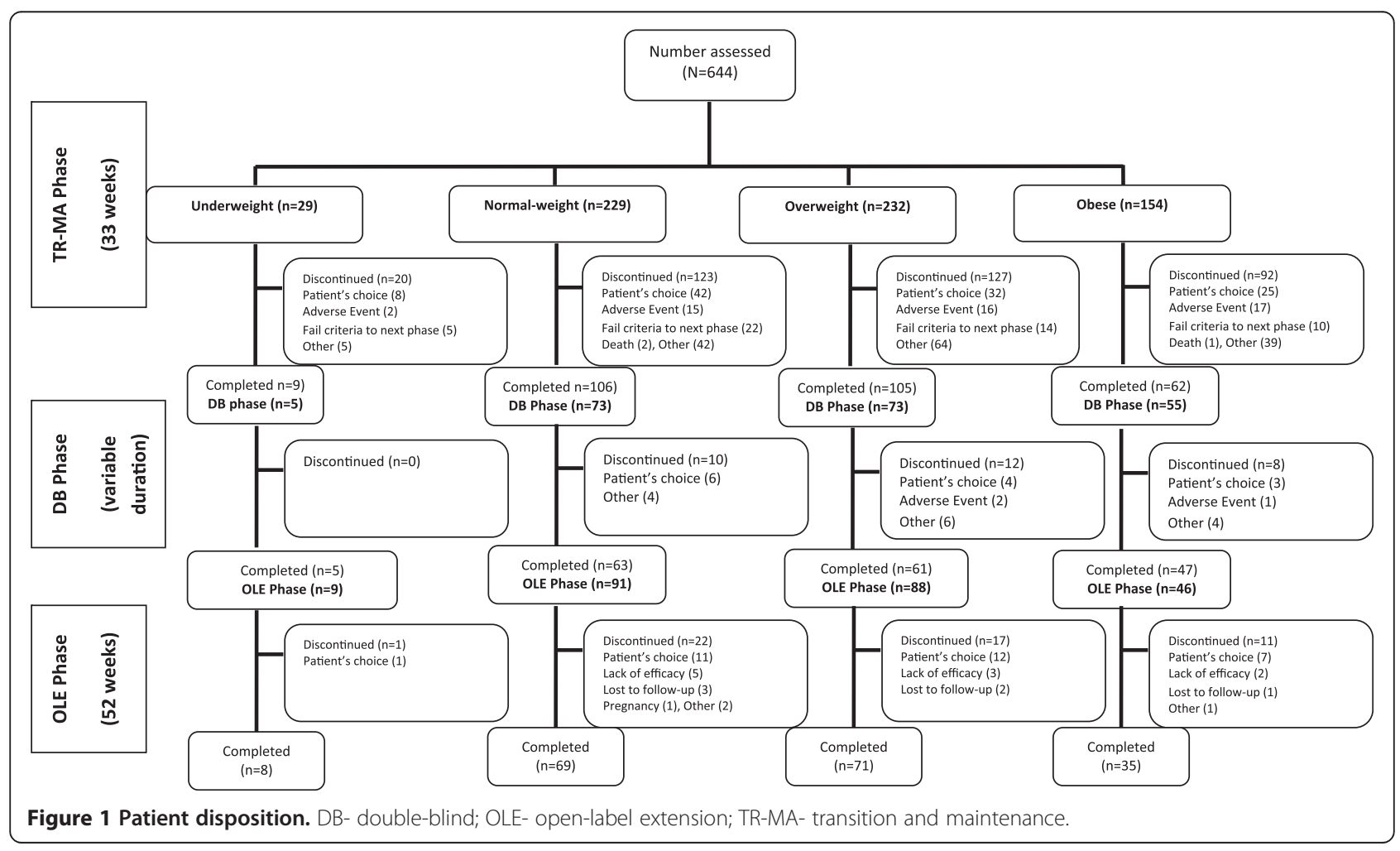


Table 1 Patient demographics and baseline characteristics (Transition baseline)

\begin{tabular}{|c|c|c|c|c|c|}
\hline Parameter & $\begin{array}{c}\text { Underweight } \\
<19 \mathrm{~kg} / \mathrm{m}^{2} \\
(\mathrm{n}=29)\end{array}$ & $\begin{array}{c}\text { Normal-weight } \\
19-<25 \mathrm{~kg} / \mathrm{m}^{2} \\
(\mathrm{n}=229)\end{array}$ & $\begin{array}{c}\text { Overweight } \\
25-<30 \mathrm{~kg} / \mathrm{m}^{2} \\
(\mathrm{n}=232)\end{array}$ & $\begin{array}{c}\text { Obese } \\
\geq 30 \mathrm{~kg} / \mathrm{m}^{2} \\
(\mathrm{n}=154)\end{array}$ & $\begin{array}{c}\text { Overall } \\
(\mathrm{N}=644)\end{array}$ \\
\hline Age (yrs), Mean (SD) & $33.2(11.20)$ & $36.2(10.57)$ & $38.2(10.85)$ & $38.4(9.81)$ & $37.3(10.58)$ \\
\hline Men, n (\%) & $19(65)$ & $146(64)$ & $143(62)$ & $71(46)$ & $379(59)$ \\
\hline \multicolumn{6}{|l|}{ Race, n (\%) } \\
\hline White & $19(66)$ & $147(64)$ & $139(60)$ & $82(53)$ & $387(60)$ \\
\hline Black & $3(10)$ & $30(13)$ & $37(16)$ & $50(32)$ & $120(19)$ \\
\hline Asian & $6(21)$ & $46(20)$ & $47(20)$ & $18(12)$ & $117(18)$ \\
\hline Other & $1(3)$ & $6(3)$ & $9(4)$ & $4(3)$ & $20(3)$ \\
\hline Baseline BMI $\left(\mathrm{kg} / \mathrm{m}^{2}\right)$, Mean (SD) & $18.0(0.87)$ & $22.5(1.52)$ & $27.1(1.34)$ & $35.4(4.68)$ & $27.0(5.88)$ \\
\hline Age at diagnosis of schizophrenia (years), Mean (SD) & $25.4(8.57)$ & $25.4(7.39)$ & $26.0(8.99)$ & $25.4(8.95)$ & $25.6(8.41)$ \\
\hline Baseline total PANSS, Mean (SD) & $77.1(17.20)$ & $71.4(17.09)$ & $72.6(18.82)$ & $72.8(16.91)$ & $72.4(17.70)$ \\
\hline \multicolumn{6}{|l|}{ Prior hospitalization, $\mathrm{n}(\%)$} \\
\hline None & $3(10)$ & $26(11)$ & $18(8)$ & $16(10)$ & $63(10)$ \\
\hline Once & $6(21)$ & $55(24)$ & $47(20)$ & $29(19)$ & $137(21)$ \\
\hline Twice & $9(31)$ & $49(21)$ & $48(21)$ & $40(26)$ & $146(23)$ \\
\hline Three times & $4(14)$ & $32(14)$ & $46(20)$ & $23(15)$ & $105(16)$ \\
\hline Four times or more & $7(24)$ & $67(29)$ & $73(31)$ & $46(30)$ & 193 (30) \\
\hline
\end{tabular}

BMI-body metabolic index; PANSS-Positive and Negative Symptom Scale score; SD-standard deviation.

232, 14.7\%) were similar. No metabolic-related TEAEs were reported in the underweight group $(\mathrm{N}=29)$. The most commonly ( $>2 \%$ ) occurring metabolic TEAEs by BMI group were weight gain (normal-weight: $11.4 \%$, overweight: $7.3 \%$, obese: $11.7 \%$ ), elevated blood glucose levels (normal-weight: $2.2 \%$, overweight: $3.9 \%$, obese: $4.6 \%$ ), and increased levels of cholesterol (normal-weight: 2.6\%, overweight: $1.3 \%$, obese: $4.6 \%$ ), triglyceride (normal-weight: $2.6 \%$, overweight: $1.3 \%$, obese: $3.9 \%$ ), low density lipoprotein (LDL) (normal-weight: $1.8 \%$, overweight: $0.4 \%$, obese: $2.6 \%$ ) and insulin (normal-weight: $0.9 \%$, overweight: 1.7\%, obese: 4.6\%) (Figure 3, Additional file 1).

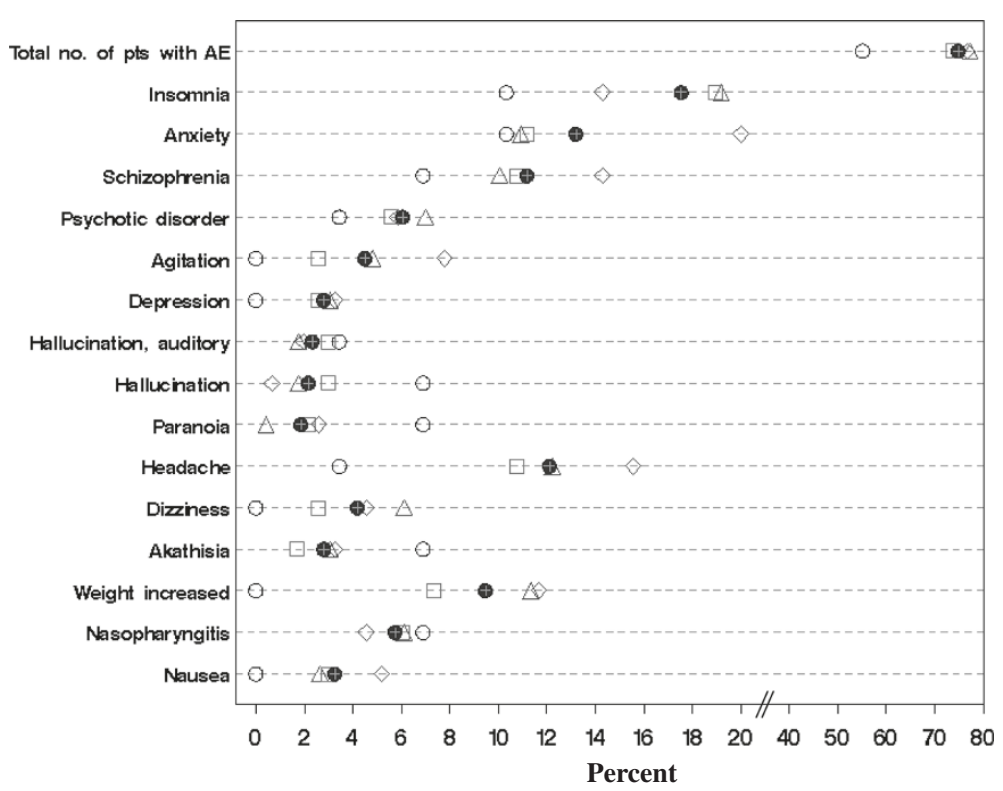

Figure 2 Treatment-emergent adverse events in $\geq 5 \%$ of patients in any BMI-based group from TR baseline to OLE endpoint. ○ Underweight $<19 \mathrm{~kg} / \mathrm{m}^{2}(\mathrm{n}=29) \Delta$ Normal-weight $19-<25 \mathrm{~kg} / \mathrm{m}^{2}(\mathrm{n}=229)$ 口 Overweight $25-<30 \diamond \mathrm{kg} / \mathrm{m}^{2}(\mathrm{n}=232)$ Obese $\geq 30 \mathrm{~kg} / \mathrm{m}^{2}$ $(n=154) \bullet$ Overall $(n=644)$. BMI- body mass index; TR- transition; OLE- open-label extension. 


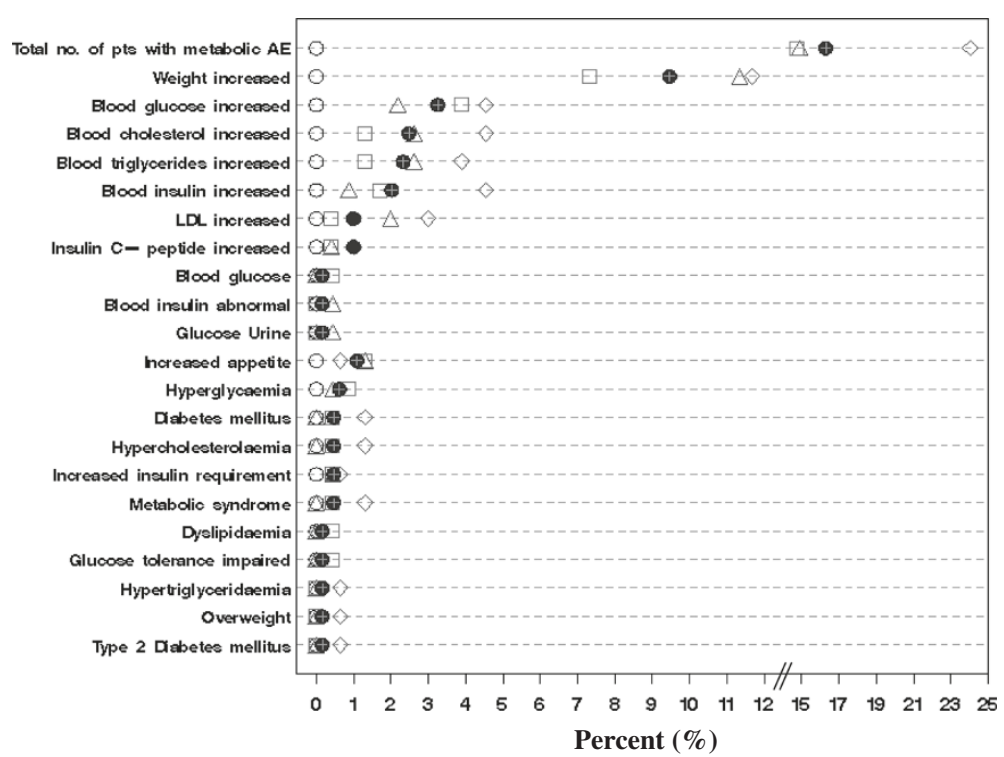

Figure 3 Metabolic-related adverse events from TR baseline to OLE endpoint. $\circ$ Underweight $<19 \mathrm{~kg} / \mathrm{m}^{2}(\mathrm{n}=29) \Delta$ Normal-weight $19-<25 \mathrm{~kg} / \mathrm{m}^{2}$ $(n=229) \square$ Overweight $25-\diamond<30 \mathrm{~kg} / \mathrm{m}^{2}(\mathrm{n}=232)$ Obese $\geq 30 \mathrm{~kg} / \mathrm{m}^{2}(\mathrm{n}=154) \bullet$ Overall $(\mathrm{n}=644)$. OLE- open-label extension; TR-transition.

\section{Change in mean weight and mean BMI}

From TR baseline to DB endpoint (a median duration of 156 days), the mean [SD] weight gain in normal-weight and overweight groups were significant (2.40 [4.99] kg; $\mathrm{p}<0.001$ and 1.68 [5.17] kg; $\mathrm{p}=0.008$, respectively) (Figure 4).

During this phase, a weight increase of $\geq 7 \%$ was observed in $5 \%$ of patients in the normal-weight and obese groups and in $8 \%$ of patients in the overweight group. From TR baseline to OLE endpoint (a median duration of 204 days, range $=6$ to 1009 days), all BMI-based groups, except the obese group (mean[SD], 0.79 [11.12] $\mathrm{kg} ; \mathrm{p}=0.645)$, showed significant increases in mean weight (mean[SD], 3.48 [5.99] kg; $\mathrm{p}<0.001$ for normalweight group; 1.62 [4.84] kg; $\mathrm{p}=0.003$ for overweight group); the increase was greatest in the underweight group (mean[SD], 3.82 [4.83] kg; $\mathrm{p}=0.0450$ ) (Figure 4). A weight increase of $\geq 7 \%$ from TR baseline to OLE endpoint was observed in $15 \%$ of patients in the normal-

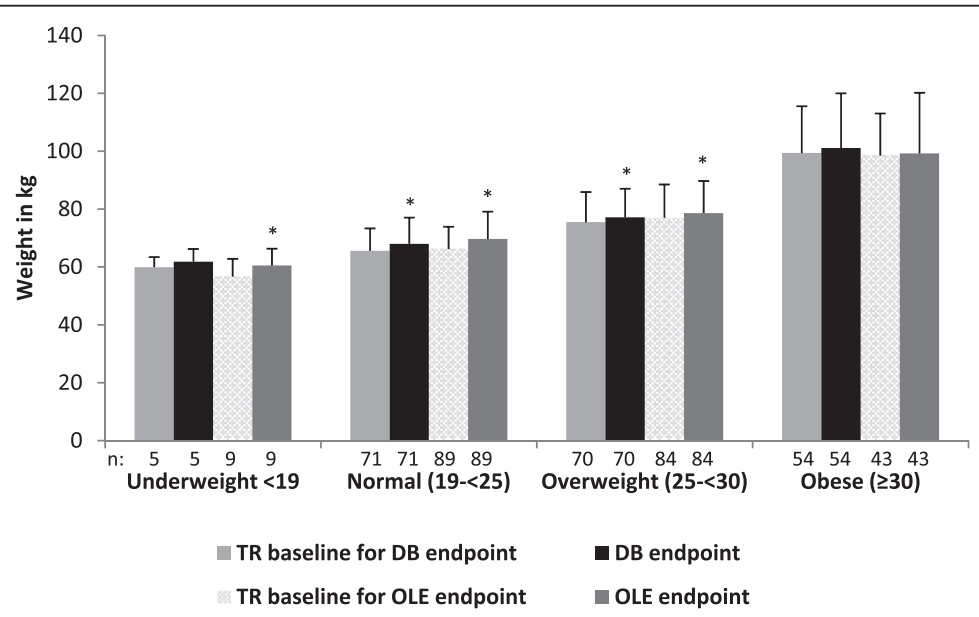

${ }^{*} \mathrm{p} \leq 0.05$.p-values are based on change from TR baseline scores and calculated using paired t-test. Baseline values are for those patients for whom both TR baseline and DB (or OLE) endpoint data were available. DB-double-blind; OLE-open-label extension; TR-transition; SD-standard deviation

Figure 4 Mean (SD) weight at TR baseline, DB endpoint and OLE endpoint (ITT analysis set). ${ }^{*} p \leq 0.05 ; p$ values are based on change from TR baseline scores and calculated using paired $t$-test. Baseline values are for those patients for whom both TR baseline and DB (or OLE) endpoint data were available. DB- double-blind; OLE- open-label extension; TR transition; SD- standard deviation. 
weight group, $4 \%$ of patients in the overweight group, and $6 \%$ of patients in the obese group.

A shift towards a higher BMI category was observed in some patients from TR baseline to DB endpoint $(60 \%$ [3/5] of patients in underweight group, 18\% [13/71] of patients in normal- weight group, and 9\% [6/70] of patients in overweight group) as well as from TR baseline to OLE endpoint (67\% [6/9] of patients in underweight group, 28\% [25/89] of patients in normal-weight group, and 16\% [11/70] of patients in overweight group) (Figure 5). However, a few patients from the overweight and obese groups moved to a lower BMI category (TR baseline to DB endpoint: 7\% [5/70] moved from overweight to normalweight group and 9\% [5/54] moved from overweight to obese group; TR baseline to OLE endpoint: 9\% [8/84] moved from overweight to normal-weight group and 19\% [8/43] moved from obese to overweight group).

\section{Changes in glucose and lipid levels}

Mean glucose levels increased significantly from TR baseline to both DB and OLE endpoints in the overweight group, and from TR baseline to OLE endpoint in the normal-weight group (Table 2). An abnormally high (>300 mg/dL; single observation meeting criteria) blood glucose level was observed in one patient each from the overweight and obese groups from TR baseline to DB endpoint. From TR baseline to OLE endpoint, 2 out of 85 patients in the normal-weight group and one out of 41 patients from obese group had abnormally high blood glucose levels (single observation meeting criteria).
The decrease in mean (SD) cholesterol $(\mathrm{mg} / \mathrm{dL})$ levels from TR baseline to DB endpoint was -10.20 (36.27) for underweight, -1.65 (28.87) for normal-weight, -8.91 (26.99) for overweight, and -17.25 (34.78) for obese groups. However, cholesterol levels increased in the normal-weight and obese groups from TR baseline to OLE endpoint (Table 2). None of the patients showed abnormal ( $>300 \mathrm{mg} / \mathrm{dL}$ ) elevation in cholesterol from TR baseline to DB endpoint and only one out of 84 patients in the normal-weight group had an abnormally high cholesterol level from TR baseline to OLE endpoint.

Mean LDL levels decreased in all the BMI groups, except the normal-weight group, from TR baseline to DB endpoint, and the reduction was numerically greater in the overweight and obese groups than in the normal and underweight groups. From TR baseline to OLE endpoint, LDL levels increased significantly $(\mathrm{p}=0.024)$ in patients from the normal-weight group (Table 2). Abnormal increases $(>160 \mathrm{mg} / \mathrm{dL})$ in LDL levels from TR baseline to DB endpoint occurred in $4 \%(2 / 45)$ of patients in the normal-weight group and 3\% (1/38) of patients in the obese group. In addition, abnormal increases in LDL levels from TR baseline to OLE endpoint occurred in $5 \%(3 / 56)$ of patients in the normal-weight group, $6 \%(3 / 53)$ of patients in the overweight group and $10 \%(3 / 30)$ of patients in the obese group.

There was no significant difference in mean insulin, high density lipoprotein (HDL) or triglyceride levels from baseline to DB and OLE endpoints throughout the study (Table 2). An abnormal increase ( $>500 \mathrm{mg} / \mathrm{dL})$ in triglyceride levels was observed in $2 \%(1 / 51)$ of patients

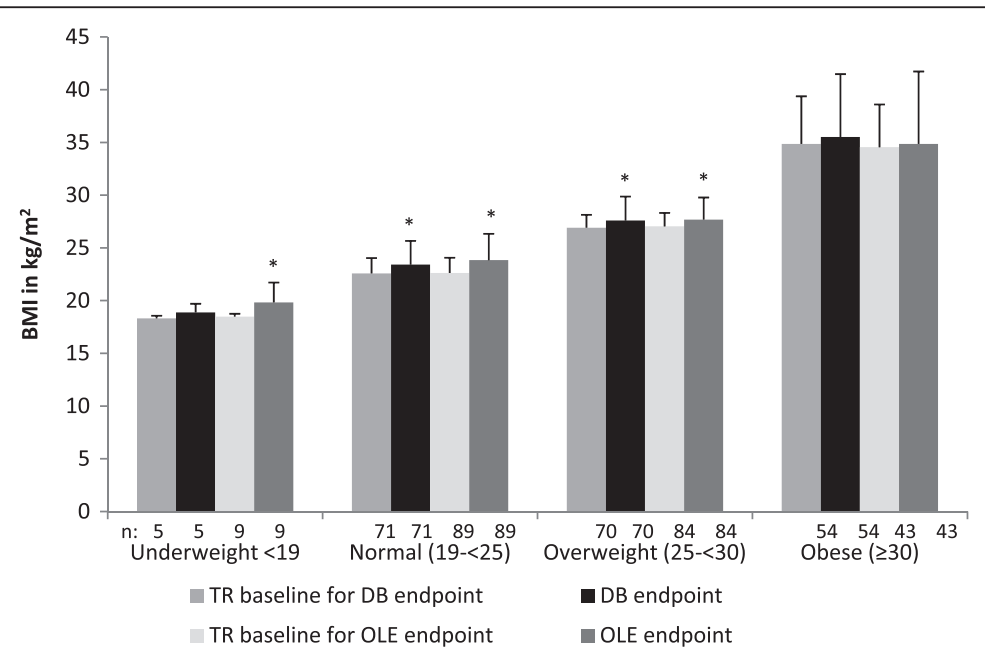

${ }^{*} \mathrm{p} \leq 0.05$. $\mathrm{p}$-values are based on change from TR baseline scores and calculated using paired t-test. Baseline values are for those patients for whom both TR baseline and DB (or OLE) endpoint data were available. DB-double-blind; OLE-open-label extension; TR- transition; SD-standard deviation

Figure 5 Mean (SD) BMI at TR baseline, DB endpoint and OLE endpoint (ITT analysis set). ${ }^{*} p \leq 0.05 ; p$ values are based on change from TR baseline scores and calculated using paired $t$-test. Baseline values are for those patients for whom both TR baseline and DB (or OLE) endpoint data were available. DB- double-blind; OLE- open-label extension; TR- transition; SD- standard deviation. 
Table 2 Metabolic parameters at TR baseline, DB endpoint and OLE endpoint (ITT analysis set)

Plasma glucose, (mg/dL)
ITT analysis set with DB endpoint
$n$
TR baseline
Change from TR baseline to DB endpoint
p-value
ITT analysis set with OLE endpoint
$n$
TR baseline
Change from TR baseline to OLE endpoint
p-value

\section{Underweight}

$<19 \mathrm{~kg} / \mathrm{m}^{2}$

Insulin, $(\mu \mathrm{U} / \mathrm{mL})$

ITT analysis set with DB endpoint

n

TR baseline

Change from TR baseline to DB endpoint

p-value

ITT analysis set with OLE endpoint

n

TR baseline

Change from TR baseline to OLE endpoint

p-value

\section{Cholesterol, (mg/dL)}

ITT analysis set with DB endpoint

n

TR baseline

Change from TR baseline to DB endpoint

p-value

ITT analysis set with OLE endpoint

n

TR baseline

Change from TR baseline to OLE endpoint

p-value

$\mathrm{HDL}$, (mg/dL)

ITT analysis set with DB endpoint

n

TR baseline

Change from TR baseline to DB endpoint

p-value

ITT analysis set with OLE endpoint

$\mathrm{n}$

TR baseline
5

$89.8(14.65)$

$14.6(18.39)$

0.1506

8

$90.4(11.22)$

3.9 (18.36)

0.5694

4

$17.0(13.44)$

$-2.5(4.36)$

0.3345

7

$12.3(11.23)$

0.3 (17.59)

0.9671

5

170.8 (27.09)

-10.2 (36.27)

0.5636

8

161.9 (26.55)

-3.25 (28.96)

0.7602
Normal-weight

$19-<25 \mathrm{~kg} / \mathrm{m}^{2}$
Overweight

$25-<30 \mathrm{~kg} / \mathrm{m}^{2}$
Obese $\geq 30 \mathrm{~kg} / \mathrm{m}^{2} \mathrm{~g}$ 
Table 2 Metabolic parameters at TR baseline, DB endpoint and OLE endpoint (ITT analysis set) (Continued)

\begin{tabular}{|c|c|c|c|c|}
\hline Change from TR baseline to OLE endpoint & $-0.2(7.92)$ & $0.3(13.46)$ & $-1.6(10.75)$ & $1.0(10.92)$ \\
\hline$p$-value & 0.9314 & 0.8095 & 0.1869 & 0.5514 \\
\hline \multicolumn{5}{|l|}{$\mathrm{LDL},(\mathrm{mg} / \mathrm{dL})$} \\
\hline \multicolumn{5}{|l|}{ ITT analysis set with DB endpoint } \\
\hline$n$ & 5 & 71 & 61 & 45 \\
\hline TR baseline & $85.4(18.80)$ & $101.7(34.37)$ & $113.2(30.01)$ & $126.3(35.45)$ \\
\hline Change from TR baseline to DB endpoint & $-6.0(23.64)$ & $0.2(26.18)$ & $-9.6(23.10)$ & $-18.8(28.82)$ \\
\hline$p$-value & 0.6007 & 0.9388 & 0.0020 & 0.0001 \\
\hline \multicolumn{5}{|l|}{ ITT analysis set with OLE endpoint } \\
\hline$n$ & 8 & 82 & 72 & 38 \\
\hline TR baseline & $83.2(20.35)$ & $99.9(30.97)$ & $113.3(28.35)$ & $122.9(28.98)$ \\
\hline Change from TR baseline to OLE endpoint & $1.7(21.67)$ & $6.8(26.86)$ & $-0.1(30.29)$ & $-2.1(20.97)$ \\
\hline$p$-value & 0.8259 & 0.0249 & 0.9814 & 0.5347 \\
\hline \multicolumn{5}{|l|}{ Triglycerides, (mg/dL) } \\
\hline \multicolumn{5}{|l|}{ ITT analysis set with DB endpoint } \\
\hline $\mathrm{n}$ & 5 & 71 & 64 & 52 \\
\hline TR baseline & $124.4(95.27)$ & $111.4(57.31)$ & $155.6(132.87)$ & $172.2(101.48)$ \\
\hline Change from TR baseline to DB endpoint & $-5.4(79.94)$ & $-1.8(54.93)$ & $-8.5(129.2)$ & $-0.8(97.12)$ \\
\hline$p$-value & 0.8872 & 0.7813 & 0.5985 & 0.9535 \\
\hline \multicolumn{5}{|l|}{ ITT analysis set with OLE endpoint } \\
\hline $\mathrm{n}$ & 8 & 85 & 75 & 40 \\
\hline TR baseline & $107.7(77.00)$ & $117.00(72.70)$ & $158.7(134.11)$ & $150.5(67.13)$ \\
\hline Change from TR baseline to OLE endpoint & $-22.6(65.95)$ & $5.3(87.44)$ & $-3.57(135.8)$ & $13.8(65.18)$ \\
\hline p-value & 0.3642 & 0.5765 & 0.8203 & 0.1875 \\
\hline
\end{tabular}

TR- transition; DB- double-blind; OLE- open-label extension; ITT- Intent-to-treat.

Changes from TR baseline to DB endpoint or OLE endpoint were calculated using data from those patients belonging to ITT analysis set with DB or OLE endpoint.

All data values are expressed as mean (SD) and $p$-values are based on change from TR baseline scores and calculated using paired $t$-test.

in the obese group from TR baseline to DB endpoint and in $1 \%(1 / 85)$ of patients in the normal-weight group from TR baseline to OLE endpoint. None of the patients showed an abnormal decrease $(<35 \mathrm{mg} / \mathrm{dL})$ in $\mathrm{HDL}$ levels throughout the study.

\section{Homeostatic model assessments}

HOMA-IR geometric mean values were $>1$ in all BMI groups at baseline, indicating preexisting insulin resistance [17]. There was minimal change in the HOMA-IR geometric mean values from TR baseline to OLE endpoint across all baseline BMI groups (Table 3). Baseline geometric mean HOMA- $\% \beta$ values were above normal (defined as $>100$ ) in overweight and obese groups, indicating higher $\beta$-cell function [17]. At OLE endpoint, HOMA- $\% \beta$ values decreased from TR baseline in the normal-weight, overweight and obese groups. In the underweight group, the HOMA- $\% \beta$ values increased from below to above normal from TR baseline to OLE end point (Table 3 ).

\section{Discussion}

Metabolic adverse effects, especially abnormal lipid and glucose metabolism, are a particular concern in patients with schizophrenia receiving SGAs [18-21]. Baseline BMI has been shown to be a potential predictor of increased risk of such metabolic events [8]. Therefore, we conducted a post hoc analysis of data from a long-term multiphase, recurrence prevention trial of PP in patients with schizophrenia $[14,15]$ to assess the occurrence of metabolic events by baseline BMI.

We found no clear pattern, by BMI group, in general TEAEs, but the obese group had the highest occurrence of metabolic-related TEAEs, indicating that higher BMI is potentially associated with higher risk of metabolic-related adverse events. Patients in the underweight group had the lowest incidence of overall TEAEs compared with other baseline BMI groups, and experienced no metabolicrelated TEAEs. Adverse changes in metabolic-related laboratory values did not appear to consistently correlate with BMI, however. Reported TEAEs (both overall and 
Table 3 HOMA-IR and HOMA-\% $\beta$ values (geometric mean and range) at TR baseline, DB and OLE endpoints

\begin{tabular}{|c|c|c|c|c|c|}
\hline & $\begin{array}{c}\text { Underweight } \\
<19 \mathrm{~kg} / \mathrm{m}^{2}\end{array}$ & $\begin{array}{l}\text { Normal-weight } \\
19-<25 \mathrm{~kg} / \mathrm{m}^{2}\end{array}$ & $\begin{array}{c}\text { Overweight } \\
25-<30 \mathrm{~kg} / \mathrm{m}^{2}\end{array}$ & $\begin{array}{c}\text { Obese } \\
\geq 30 \mathrm{~kg} / \mathrm{m}^{2}\end{array}$ & Overall \\
\hline \multicolumn{6}{|l|}{ HOMA-IR } \\
\hline \multicolumn{6}{|l|}{ TR baseline } \\
\hline $\mathrm{N}$ & 22 & 191 & 200 & 133 & 546 \\
\hline Geometric Mean & 1.5 & 1.7 & 2.4 & 4.3 & 2.4 \\
\hline Range & $(0.66,3.56)$ & $(0.74,3.99)$ & $(1.11,5.14)$ & $(1.86,9.85)$ & $(0.99,5.85)$ \\
\hline \multicolumn{6}{|l|}{ DB endpoint } \\
\hline$N$ & 4 & 62 & 60 & 52 & 178 \\
\hline Geometric Mean & 2.5 & 2.0 & 2.6 & 3.8 & 2.6 \\
\hline Range & $(0.75,8.17)$ & $(0.84,4.64)$ & $(1.13,5.80)$ & $(1.64,8.86)$ & $(1.09,6.33)$ \\
\hline \multicolumn{6}{|l|}{ OLE endpoint } \\
\hline $\mathrm{N}$ & 8 & 76 & 71 & 40 & 195 \\
\hline Geometric Mean & 1.9 & 2.0 & 2.6 & 4.2 & 2.6 \\
\hline Range & $(0.73,4.81)$ & $(0.78,5.03)$ & $(0.99,6.97)$ & $(2.19,8.25)$ & $(1.00,6.56)$ \\
\hline \multicolumn{6}{|l|}{ НОМА- $\% \beta$} \\
\hline \multicolumn{6}{|l|}{ TR baseline } \\
\hline $\mathrm{N}$ & 22 & 191 & 200 & 133 & 546 \\
\hline Geometric Mean & 90.4 & 93.8 & 123.4 & 175.9 & 120.7 \\
\hline Range & $(50.65,161.25)$ & $(46.18,190.64)$ & $(63.20,240.9)$ & $(82.53,374.68)$ & $(57.47,53.47)$ \\
\hline \multicolumn{6}{|l|}{ DB endpoint } \\
\hline $\mathrm{N}$ & 4 & 62 & 60 & 52 & 178 \\
\hline Geometric Mean & 84.7 & 100.2 & 105.9 & 167.1 & 118.1 \\
\hline Range & $(21.50,333.65)$ & $(46.54,215.73)$ & $(59.91,187.1)$ & $(88.5,315.3)$ & $(57.8,241.2)$ \\
\hline \multicolumn{6}{|l|}{ OLE endpoint } \\
\hline $\mathrm{N}$ & 8 & 76 & 71 & 40 & 195 \\
\hline Geometric Mean & 117.0 & 91.0 & 100.8 & 167.9 & 108.2 \\
\hline Range & $(50.71,270.77)$ & $(35.65,232.06)$ & $(47.68,213.29)$ & $(91.04,309.64)$ & $(46.99,49.21)$ \\
\hline
\end{tabular}

TR- transition; DB- double-blind; OLE- open-label extension.

HOMA-IR = Homeostatic Model Assessment for Insulin Resistance; HOMA- $\% \beta=$ Homeostatic Model Assessment for $\beta$-cell function. *HOMA-IR and HOMA-\% $\beta$ are expressed as the Geometric Mean (exp [mean $\{\log s\}-1 *$ SD $\{\log s\}]$, exp [mean $\{\log s\}+1$ * SD $\{\log \}\}]$ ).

metabolic) in this study were consistent with the safety findings of previous studies of PP [22-25].

Weight gain, a common problem of antipsychotic medication, may lead to noncompliance and certain comorbidities such as dyslipidemia, hypertension, diabetes mellitus, cardiovascular disease, cancers, and osteoarthritis $[9,26]$. A previous meta-analysis demonstrated a mean increase in weight in patients receiving standard doses of antipsychotics over a 10-week period: $4.45 \mathrm{~kg}$ with clozapine, $4.15 \mathrm{~kg}$ with olanzapine, $2.92 \mathrm{~kg}$ with sertindole, $2.10 \mathrm{~kg}$ with risperidone, and $0.04 \mathrm{~kg}$ with ziprasidone [27]. A double-blind randomized clinical trial comparing three SGAs in patients early in the course of psychotic illness found that at week 12, the olanzapine group had more weight gain, a greater increase in BMI, and a higher proportion of patients with a BMI increase of at least 1 unit compared with the quetiapine and risperidone groups.
Furthermore, $80 \%$ of patients in the olanzapine group had gained $\geq 7 \%$ of their baseline weight at week 52 , compared with $50 \%$ in the quetiapine and $58 \%$ in the risperidone groups [21]. In the present post hoc analysis, moderate weight gain $(0.8-3.8 \mathrm{~kg})$ was observed during the much longer study period (median $=204$ days, range $=6$ to 1009 days). More patients in the normal-weight group had $>7 \%$ weight gain compared with all other groups. Even though none of the patients in the underweight group had $>7 \%$ weight gain, $60 \%$ of these patients gained weight and thus achieved normal-weight. More than $50 \%$ of patients were followed up to 6 months and $40 \%$ of patients were followed up to a year. Although we were unable to follow these patients long enough to determine how the course of their weight gain may continue to change over time, it is possible these patients' weight trajectory may follow that of other 
patients with increasing metabolic disturbance occurring during the course of treatment. The weight gain observed in this analysis is comparable to that observed in previous short-term PP studies, where moderate weight gain $(0.9-1.5 \mathrm{~kg})$ was observed over a 13week period [18-20]. Similar findings were also seen in long-term studies with oral paliperidone extended-release, which showed a mean (SD) increase in body weight of 1.2 (5.16) $\mathrm{kg}$ from OLE baseline to OLE endpoint [28]. Long-term double-blind, placebocontrolled schizophrenia relapse prevention studies with PP and paliperidone extended-release have shown that increase in body weight is similar between PP and paliperidone extended-release [29]. The mean weight gain observed in the present study is thus parallel to data presented for OLE and short term PP studies. A prospective study examining the use of PP with weight reduction or weight maintenance programs would be valuable.

In addition to their effects on weight gain, SGAs are often associated with abnormal glucose regulation $[2,9,16]$. In the present study, there were no clinically relevant mean changes in the glucose and serum lipid levels across baseline BMI groups, similar to findings of earlier short-term PP studies [22-25]. Previous long-term PP studies also noted a low proportion of glucose-related TEAEs [24,25]. Further, no clinically relevant lipid changes were observed in a long-term study with the highest available dose of PP (150 mg eq.) [30].

The result of this post hoc analysis should be interpreted cautiously, as the study was not designed or powered to demonstrate differences in metabolic-related TEAEs in subgroups defined by baseline BMI. Additionally, preexisting risk factors in the obese group for metabolic events may contribute to the higher incidence of metabolic-related TEAEs in this group. The results may not be broadly applicable to the full spectrum of patients with schizophrenia due to the specific recruitment criteria for the study, and substantially smaller sample size for the underweight group. Patients with schizophrenia are at increased risk for metabolic abnormalities and schizophrenia treatment seems to exacerbate this risk; these effects could not be assessed in the current study due to lack of a control arm.

\section{Conclusion}

This study, with a median duration of PP exposure of 204 days, suggests that occurrences of metabolic-related TEAEs trend with greater BMI status in patients with schizophrenia treated with PP. Consistent trends in metabolic-related laboratory values with BMI status were not observed. Prespecified studies are needed to confirm these results.

\section{Additional file}

Additional file 1: Supplemental information: appendix 1. MedRA terminology for TEAEs listed in the manuscript.

\section{Competing interests}

Drs. Alphs, Bossie, Fu and Sliwa are employees of Janssen Scientific Affairs, LLC. Mr. Turkoz is employee of Janssen Research \& Development, LLC. The Janssen companies are Johnson \& Johnson companies. All authors hold stocks in Johnson \& Johnson. All authors meet ICMJE criteria and all those who fulfilled those criteria are listed as authors. All authors had access to the study data and made the final decision about where to publish these data and approved submission to this journal.

\section{Authors' contributions}

All authors gave substantial contribution to conception and interpretation of data. Dr. IT was the statistician for this post hoc analysis contributing to analysis of data. All authors reviewed and critically revised the manuscript for important intellectual content. All authors approved the final manuscript.

\section{Acknowledgments}

The study was funded by Janssen Scientific Affairs, LLC, Raritan, N.J., USA, a Johnson \& Johnson company. Dr. Polverejan and Mr. Todd conducted the analysis. Ms. Vijayalakshmi Vasanthaprasad and Dr. Strayo De Agarwal (SIRO Clinpharm Pvt Ltd) provided writing assistance for this manuscript; Dr. Wendy P. Battisti (Janssen Research \& Development, LLC) provided additional editorial support and review.

The authors also thank the study participants, without whom this study would never have been accomplished, and the investigators (Hough et al., 2010; Gopal et al., 2010a) for their participation in this study.

\section{Funding}

Supported by funding from Janssen Scientific Affairs, LLC. The sponsor also provided a formal review of this manuscript.

\section{Previous presentations}

The primary data from this study are published. The data presented in this manuscript were previously presented at the $165^{\text {th }}$ Annual Meeting of the American Psychiatric Association, May 5-9, 2012, Philadelphia, PA, USA.

\section{Author details}

'Janssen Scientific Affairs, LLC, NJ, USA. Janssen Research \& Development, LLC, NJ, USA.

Received: 21 March 2013 Accepted: 17 February 2014

Published: 22 February 2014

\section{References}

1. Schultz SH, North SW, Shields CG: Schizophrenia: a review. Am Fam Physician 2007, 75(12):1821-1829.

2. Balf G, Stewart TD, Whitehead R, Baker RA: Metabolic adverse events in patients with mental illness treated with antipsychotics: a primary care perspective. Prim Care Companion J Clin Psychiatry 2008, 10(1):15-24.

3. Mclntyre RS, McCann SM, Kennedy SH: Antipsychotic metabolic effects: weight gain, diabetes mellitus, and lipid abnormalities. Can J Psychiatry 2001, 46(3):273-281.

4. Croarkin PE, Jacobs KM, Bain BK: Diabetic ketoacidosis associated with risperidone treatment? Psychosomatics 2000, 41(4):369-370.

5. Hedenmalm K, Hagg S, Stahl M, Mortimer O, Spigset O: Glucose intolerance with atypical antipsychotics. Drug Saf 2002, 25(15):1107-1116.

6. Lindenmayer JP, Czobor P, Volavka J, Citrome L, Sheitman B, McEvoy JP, Cooper TB, Chakos M, Lieberman JA: Changes in glucose and cholesterol levels in patients with schizophrenia treated with typical or atypical antipsychotics. Am J Psychiatry 2003, 160(2):290-296.

7. McEvoy JP, Meyer JM, Goff DC, Nasrallah HA, Davis SM, Sullivan L, Meltzer HY, Hsiao J, Scott Stroup T, Lieberman JA: Prevalence of the metabolic syndrome in patients with schizophrenia: baseline results from the clinical antipsychotic trials of intervention effectiveness (CATIE) schizophrenia trial and comparison with national estimates from NHANES III. Schizophr Res 2005, 80(1):19-32. 
8. Falissard B, Mauri M, Shaw K, Wetterling T, Doble A, Giudicelli A, De Hert M: The METEOR study: frequency of metabolic disorders in patients with schizophrenia. Focus on first and second generation and level of risk of antipsychotic drugs. Int Clin Psychopharmacol 2011, 26(6):291-302.

9. Tschoner A, Engl J, Laimer M, Kaser S, Rettenbacher M, Fleischhacker WW, Patsch JR, Ebenbichler CF: Metabolic side effects of antipsychotic medication. Int J Clin Pract 2007, 61(8):1356-1370.

10. Lean ME, Pajonk FG: Patients on atypical antipsychotic drugs: another high-risk group for type 2 diabetes. Diabetes Care 2003, 26(5):1597-1605.

11. Marder SR, Essock SM, Miller AL, Buchanan RW, Casey DE, Davis JM, Kane JM, Lieberman JA, Schooler NR, Covell N, Stroup S, Weissman EM, Wirshing DA, Hall CS, Pogach L, Pi-Sunyer X, Bigger JT Jr, Friedman A, Kleinberg D, Yevich SJ, Davis B, Shon S: Physical health monitoring of patients with schizophrenia. Am J Psychiatry 2004, 161(8):1334-1349.

12. American Diabetes Association: Consensus development conference on antipsychotic drugs and obesity and diabetes. Diabetes Care 2004, 27(2):596-601.

13. INVEGA ${ }^{\oplus}$ SUSTENNA ${ }^{\oplus}$ Prescribing Information: INVEGA ${ }^{\oplus}$ SUSTENNA ${ }^{\oplus}$ paliperidone palmitate prescribing information September 2011. 2011. (Accessed on 27 April 2012) Available at: http://www.invegasustenna.com/ important-product-information.

14. Hough D, Gopal S, Vijapurkar U, Lim P, Morozova M, Eerdekens M: Paliperidone palmitate maintenance treatment in delaying the time-to-relapse in patients with schizophrenia: a randomized, double-blind, placebo-controlled study. Schizophr Res 2010, 116(2-3):107-117.

15. Gopal S, Vijapurkar U, Lim P, Morozova M, Eerdekens M, Hough D: A 52-week open-label study of the safety and tolerability of paliperidone palmitate in patients with schizophrenia. J Psychopharmacol 2010, 25(5):685-697.

16. Matthews DR, Hosker JP, Rudenski AS, Naylor BA, Treacher DF, Turner RC: Homeostasis model assessment: insulin resistance and beta-cell function from fasting plasma glucose and insulin concentrations in man. Diabetologia 1985, 28(7):412-419.

17. Wallace TM, Levy JC, Matthews DR: Use and abuse of HOMA modeling. Diabetes Care 2004, 27(6):1487-1495.

18. Kagal UA, Torgal SS, Patil NM, Malleshappa A: Prevalence of the metabolic syndrome in schizophrenic patients receiving second-generation antipsychotic agents-a cross-sectional study. J Pharm Pract 2012, 25(3):368-373. Epub 2012.

19. Pramyothin $P$, Khaodhiar L: Metabolic syndrome with the atypical antipsychotics. Curr Opin Endocrinol Diabetes Obes 2010, 17(5):460-466.

20. Olfson M, Marcus SC, Corey-Lisle P, Tuomari AV, Hines P, L'Italien GJ: Hyperlipidemia following treatment with antipsychotic medications. Am J Psychiatry 2006, 163(10):1821-1825.

21. McEvoy JP, Lieberman JA, Perkins DO, Hamer RM, Gu H, Lazarus A, Sweitzer D, Olexy C, Weiden P, Strakowski SD: Efficacy and tolerability of olanzapine, quetiapine, and risperidone in the treatment of early psychosis: a randomized, double-blind 52-week comparison. Am J Psychiatry 2007, 164(7):1050-1060.

22. Gopal S, Hough DW, Xu H, Lull JM, Gassmann-Mayer C, Remmerie BM, Eerdekens $\mathrm{MH}$, Brown DW: Efficacy and safety of paliperidone palmitate in adult patients with acutely symptomatic schizophrenia: a randomized, double-blind, placebo-controlled, dose-response study. Int Clin Psychopharmacol 2010, 25(5):247-256.

23. Kramer M, Litman R, Hough D, Lane R, Lim P, Liu Y, Eerdekens M: Paliperidone palmitate, a potential long-acting treatment for patients with schizophrenia. Results of a randomized, double-blind, placebo-controlled efficacy and safety study. Int I Neuropsychopharmacol 2010, 13(5):635-647.

24. Nasrallah HA, Gopal S, Gassmann-Mayer C, Quiroz JA, Lim P, Eerdekens M, Yuen E, Hough D: A controlled, evidence-based trial of paliperidone palmitate, a long-acting injectable antipsychotic, in schizophrenia. Neuropsychopharmacology 2010, 35(10):2072-2082.

25. Pandina GJ, Lindenmayer JP, Lull J, Lim P, Gopal S, Herben V, Kusumakar V Yuen $\mathrm{E}$, Palumbo J: A randomized, placebo-controlled study to assess the efficacy and safety of 3 doses of paliperidone palmitate in adults with acutely exacerbated schizophrenia. J Clin Psychopharmacol 2010, 30(3):235-244.

26. Ucok A, Gaebel W: Side effects of atypical antipsychotics: a brief overview. World Psychiatry 2008, 7(1):58-62.

27. Allison DB, Casey DE: Antipsychotic-induced weight gain: a review of the literature. J Clin Psychiatry 2001, 62(Suppl 7):22-31.
28. Emsley R, Oosthuizen P, Koen L, Niehaus DJ, Medori R, Rabinowitz J: Oral versus injectable antipsychotic treatment in early psychosis: post hoc comparison of two studies. Clin Ther 2008, 30(12):2378-2386.

29. Markowitz M, Fu DJ, Levitan B, Gopal S, Turkoz I, Alphs L: Long-acting injectable paliperidone palmitate versus oral paliperidone extended release: a comparative analysis from two placebo-controlled relapse prevention studies. Ann Gen Psychiatry 2013, 12(1):22.

30. Coppola D, Liu Y, Gopal S, Remmerie B, Samtani MN, Hough DW, Nuamah I, Sulaiman A, Pandina G: A one-year prospective study of the safety, tolerability and pharmacokinetics of the highest available dose of paliperidone palmitate in patients with schizophrenia. BMC Psychiatry 2012, 12:26. doi:10.1186/1471-1244X-1112-1126.

doi:10.1186/1471-244X-14-52

Cite this article as: Sliwa et al.: Body mass index and metabolic

parameters in patients with schizophrenia during long-term treatment with paliperidone palmitate. BMC Psychiatry 2014 14:52.

\section{Submit your next manuscript to BioMed Central and take full advantage of:}

- Convenient online submission

- Thorough peer review

- No space constraints or color figure charges

- Immediate publication on acceptance

- Inclusion in PubMed, CAS, Scopus and Google Scholar

- Research which is freely available for redistribution 